\title{
Lemon Juice and Microwave Assisted Modification of Potato Peel Husk for Lead Biosorption: Batch and Column Studies
}

\author{
Tahira Moeen Khan*, Iram Riaz, Shahana Ehsan, Bushra Khan and Sunbal Asif \\ Department of Chemistry, Lahore College for Women University, Jail Road, Lahore, Pakistan. \\ *Corresponding Author Email: tahira.moeen@lcwu.edu.pk \\ Received 20 May 2019, Revised 29 May 2020, Accepted 11 June 2020
}

\begin{abstract}
The removal of heavy metals from water is very difficult. For this reason different methods have been employed so far among which biosorption is the cheapest and ecofriendly way to treat and remove heavy metals from aqueous media. Present study, investigated the ability of potato peel husk (PPH), potato peel husk modified with lemon juice (LMPPH) and potato peel husk modified with lemon juice \& microwave (MLMPPH) for the removal of $\mathrm{Pb}$ (II) from water. Organic adsorbent was activated by lemon juice \& microwave and was characterized by SEM, EDX and FTIR. Adsorption mechanism (batch parameters) and isothermal studies (Langmuir, Freundlich, Temkin isotherms) revealed the best fitness of Freundlich isotherm from the $\mathrm{R}^{2}$ values indicating physisorption. Results of kinetic studies (pseudo first and second order and intraparticle diffusion) showed that reaction followed pseudo second order kinetics. In thermodynamic study reaction was exothermic ( $\triangle \mathrm{H}$ was negative). The ability of PPH, LMPPH and MLMPPH for removal of lead was also investigated in column studies (bed height, flow rate, influent concentration).Thomas Morrison adsorption model described breakthrough data. Recent study proved that activation of potato peel husk with lemon juice and microwave (MLMPPH) not only increased the sorption capacity of sorbent much more as compared to PPH and LMPPH due to the introduction of excess $\mathrm{COOH}$ groups with lemon juice but also their activation as $\mathrm{COO}^{-}$with microwave exposure.
\end{abstract}

Keywords: Biosorption, PPH, Natural modification, SEM, EDX, Batch studies, Column studies.

\section{Introduction}

Shortage of potable water due to its rational use and its pollution due to heavy metals has become a serious problem nowadays. Different anthropogenic and natural sources are responsible for water pollution [1-4].

It is the need of the day to treat \& control heavy metals sources to reduce these toxicants from the environment [5- 6] as they are nonbiodegradable and tend to accumulate causing various ill effects in living organisms [2, 7, 8].Various methods have been adopted for heavy metal removal from aqueous medium (electrochemical treatment, electrocoagulation, membrane filtration, ion exchange \& photocatalytic process etc) $[4,9$ 12]. These methods are reported to be less efficient and produce hazardous by products [1, 12- 13].

To overcome these drawbacks adsorption is another method adopted for heavy metal removal from aqueous medium [11, 14 - 17]. Various biomaterials, industrial wastes, activated carbons, microorganisms, zeolites, nanomaterials, clay minerals can be selected as adsorbent $[1,8$, 14,18 - 20].

In addition to these methods, bio sorption by agricultural by products and plant wastes like rice husk ash [21], coconut shell [22], almond shell [23], tea waste [24], Moringa oleifera bark [25], wheat straw [26], banana peel [27] and 
mango peels [28] has become very popular because of their excess availability, low or no cost and high binding capacity for metals.

Agricultural wastes (lignin, cellulose, hemicellulose, extractives, lipids, proteins, sugars) are well known for their metal uptake capacity either in simple or in modified form. Biosorption by these agricultural wastes are attributed to the presence [29], activation and modification of various groups [30]. These groups like carboxyl, amide, amino, sulphonic when introduced or activated can enhance the adsorption power of adsorbent [31].

The biosorbents can be activated by using different chemicals like $\mathrm{FeCl}_{3}, \mathrm{ZnCl}_{2}$ [32], $\mathrm{H}_{2} \mathrm{O}_{2}$, $\mathrm{H}_{2} \mathrm{SO}_{4}, \mathrm{NaOH}$ [33- 34], citric acid, tartaric acid, $\mathrm{HCl}, \mathrm{HNO}_{3}, \mathrm{KOH}$, acetone, ethanol, chloroform, polymerization, tetra ethylene glycol, diethyl ether, glycol [35, 36] , urea [37] and thiourea [38]. Potato solanum tuberosum (family solanaceae) is the fourth largest crop in the world. There are 5000 varieties of potatoes worldwide. The potato peel is a waste and can be used as a biosorbent due to its abundance, easy availability, minute or no cost and its ability to uptake metal ions from aqueous solution. In this present research three types of biosorbents unmodified potato peel husk (PPH), modified potato peel husk with lemon juice (LMPPH) \& microwave assisted lemon juice modified potato peel husk (MLMPPH) were used for the first time as a new biosorbent and its modification with lemon juice is totally ecofriendly instead of using various chemicals as modifiers or activators.

By adding lemon juice (ascorbic acid) there is the introduction of additional $-\mathrm{COOH}$ groups on adsorbent surface (potato peel) and with microwave radiation these groups are much more activated as $\mathrm{COO}^{-}$providing more adsorbent sites for $\mathrm{Pb}$ (II) removal. This present research is totally eco-friendly using no chemicals and is economical by utilizing the agricultural waste.

The capability of unmodified $\mathrm{PPH}$, LMPPH \& MLMPPH of Pb (II) removal can be checked by studying isothermal, kinetic, batch \& column studies.

\section{Materials and Methods}

$\mathrm{HCl}(0.1 \mathrm{M}), \mathrm{NaOH}(0.1 \mathrm{M}), \mathrm{PbNO}_{3}(1 \mathrm{M})$ were purchased from Sigma. FTIR spectrometer, shaker, pH meter, Microwave oven (2, $450 \mathrm{MHz}$ ), Atomic Absorption Spectrometer, SEM and EDX instruments were used for analysis and characterization.

\section{Preparation of potato peel husk (PPH)}

Potato peels $(600 \mathrm{~g})$ were converted to PPH when washed, dried, grinded and sieved (ASTM 60 mesh) to form husk and then stored in a jar for further experiments.

Preparation of lemon juice modified potato peel husk (LMPPH)

$200 \mathrm{~g}$ PPH with lemon juice $(1: 2)$ were subjected to shaker at $100 \mathrm{rpm}$. After about 60 min. It is filtered and dried $\left(75^{\circ} \mathrm{C}\right)$. This dried husk was LMPPH (lemon juice modified Potato Peel Husk).

\section{Preparation of microwave lemon juice modified potato peel husk (MLMPPH)}

PPH $200 \mathrm{~g}$ and lemon juice $(1: 1)$ were first irradiated with microwave radiation $(2,450$ $\mathrm{MHz}$ ) for $20 \mathrm{~min}$. It was then boiled (30 min) using double distilled water, filtered and again washed $(20 \mathrm{~mL}$ hot double distilled water). This organic mass was then dried $\left(50^{\circ} \mathrm{C}\right.$ for $\left.6 \mathrm{~h}\right)$ to get MLMPPH (Scheme 1).

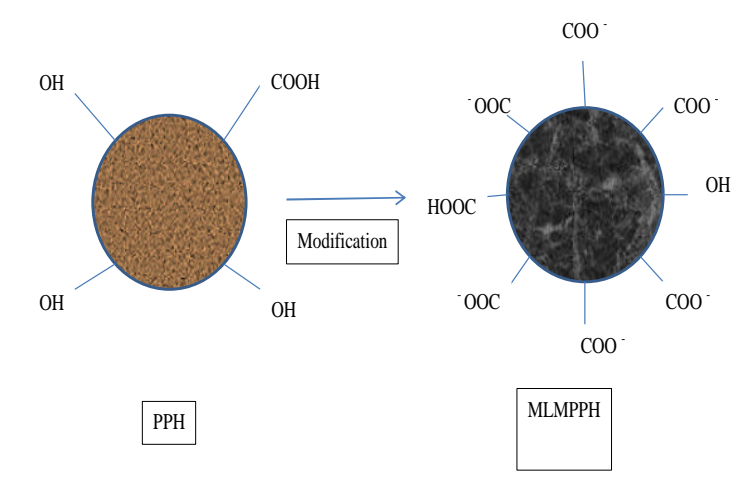

Scheme 1: Surface modification of PPH with lemon juice \& microwave activation 


\section{Preparation of lead nitrate solution}

1 M standard lead nitrate solution and other working standards were made in double distilled water and their $\mathrm{pH}$ was adjusted with 0.1 $\mathrm{M} \mathrm{HCl}$ and $\mathrm{NaOH}$.

\section{Results and Discussion FTIR Analysis}

FTIR analysis of PPH, LMPPH and MLMPPH showed different functional groups before and after activation Fig. 1. In case of LMPPH an additional peak in the region of 694.37 $\mathrm{cm}^{-1}$ showed the presence of triple bond (alkynes) which was not present in PPH. LMPPH showed additional carboxylic acid peaks with $\mathrm{OH}$ in the region of $1751.36 \mathrm{~cm}^{-1}$ and $972.12 \mathrm{~cm}^{-1}$. This peak $972.12 \mathrm{~cm}^{-1}$ was shifted to $979.84 \mathrm{~cm}^{-1}$ after microwave activation of LMPPH. Peak at 1597.06 $\mathrm{cm}^{-1}$ was due to aromatics with C-C stretch and at $2314.58 \mathrm{~cm}^{-1}$ with $\mathrm{C}$ triple bond $\mathrm{N}$ stretch which only appeared in MLMPPH. Peak at $1049.28 \mathrm{~cm}^{-1}$ is of C-N stretching in PPH and LMPPH which was shifted to $1056.99 \mathrm{~cm}^{-1}$ in case of MLMPPH. Peak of $1651.07 \mathrm{~cm}^{-1}$ showed presence of $\mathrm{C}=\mathrm{O}$ on the surface of $\mathrm{PPH}$ and after microwave activation of LMPPH it was shifted to $1674.21 \mathrm{~cm}^{-1}$. Carboxylate ion peak were at $1512.19 \mathrm{~cm}^{-1}$, $1342.46 \mathrm{~cm}^{-1}, 1273.02 \mathrm{~cm}^{-1}$ and $1172.72 \mathrm{~cm}^{-1}$ [39]. The presence of all these groups were responsible for chelation of cations from water.

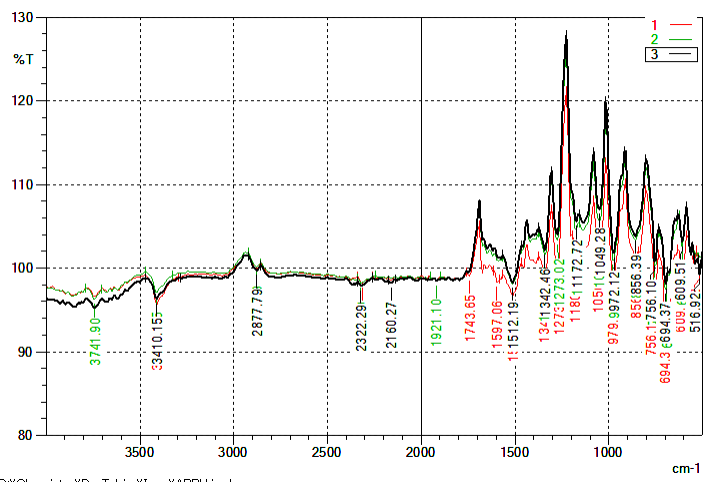

Figure 1. Over lay FTIR spectra of MLMPPH (1), PPH (2), LMPPH (3)

\section{SEM analysis}

SEM image of PPH showed the surface of
$\mathrm{PPH}$ as porous and rough. After lemon juice treatment its surface become more porous (LMPPH) having small opening with wavy edges. After microwave treatment MLMPPH particles was not only porous, irregular with wavy edges but also have very small size thus providing large surface for binding with metal ions than PPH and LMPPH Fig. 2a-c. Thus treatment and modification with lemon juice and microwave radiation boosted the binding capacity of $\mathrm{PPH}$ [40- 41] and in turn the biosorption.

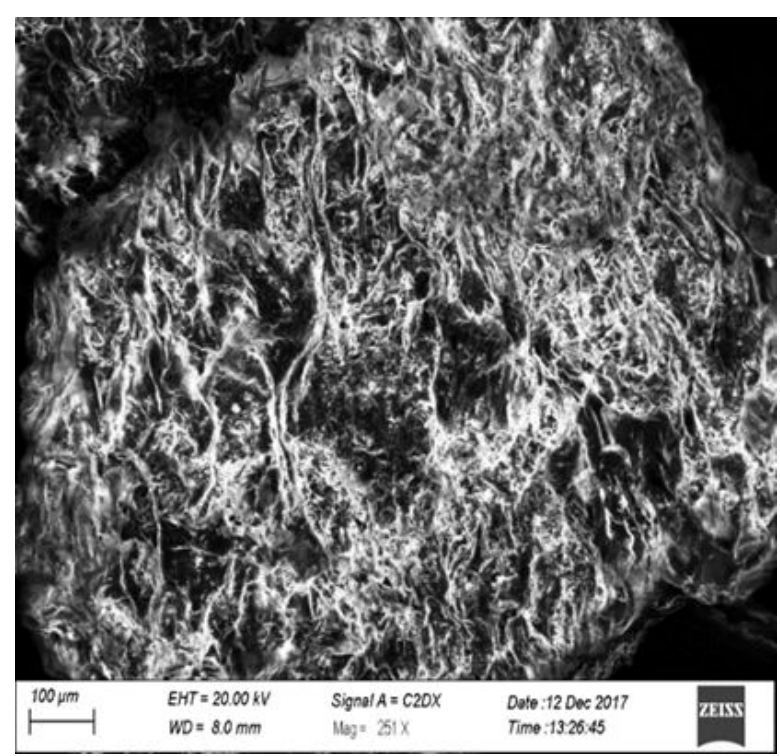

Figure 2a. SEM image of the surface PPH

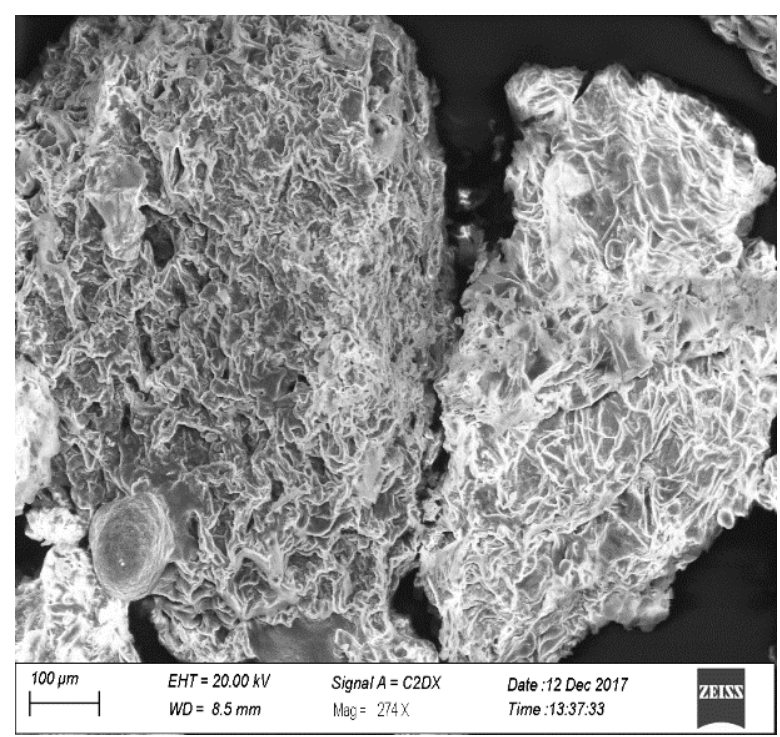

Figure $2 b$. SEM image of the surface LMPPH 


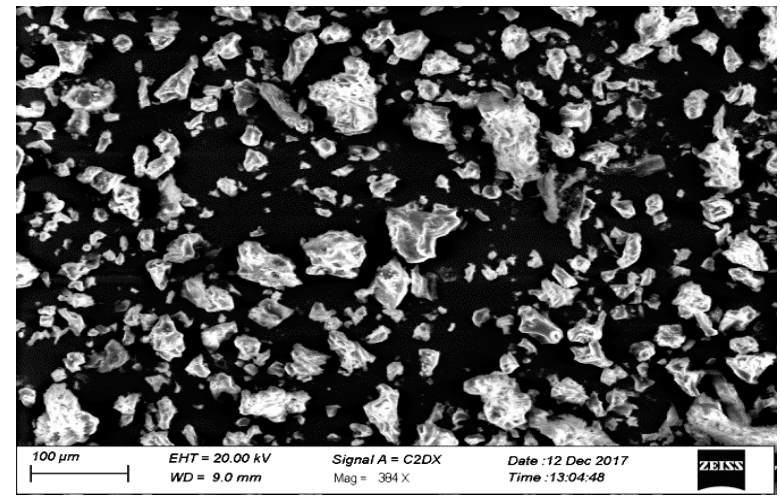

Figure 2c. SEM image of the surface MLMPPH

\section{EDX analysis}

EDX image of PPH shows its elemental composition as having $\mathrm{Ca}, \mathrm{K}, \mathrm{Na}$ and no $\mathrm{Pb}$ but for MLMPPH an additional prominent peak is observed due to retention of lead on the surface of biosorbent Fig. 3a-b.

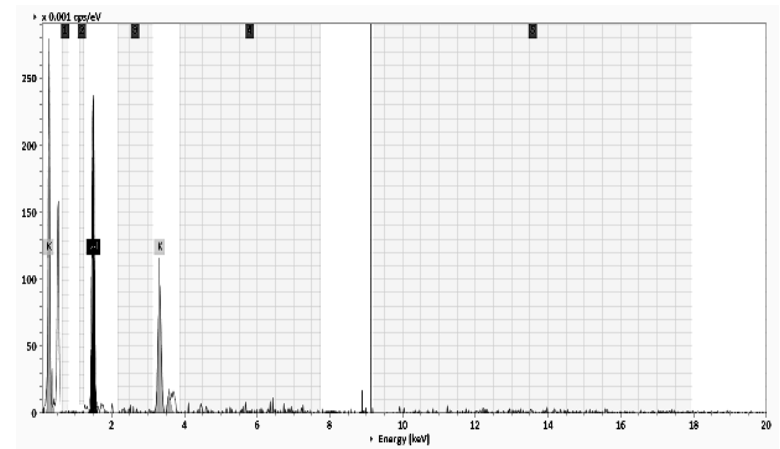

Figure 3a. EDX image of Pure PPH without lead

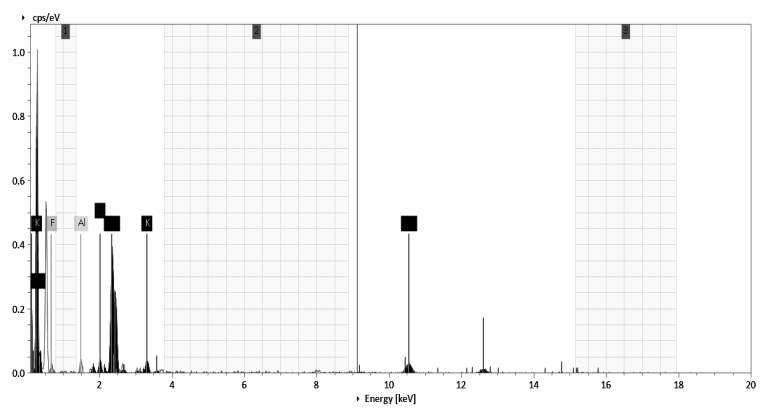

Figure 3b. EDX image of MLMPPH with lead

Batch study with PPH, LMPPH \& MLMPPH Shaking speed

To study the ability of PPH, LMPPH \& MLMPPH against $\mathrm{Pb}$ (II) removal different shaking speeds $(50,100-450 \mathrm{rpm}$ for $30 \mathrm{~min}$ was set with sorbate concentration of $25 \mathrm{ppm} / 50 \mathrm{~mL}$. It was observed that $100 \mathrm{rpm}$ shaking speed was best for PPH \& MLMPPH and $150 \mathrm{rpm}$ for LMPPH having removal percentage of $83 \%, 85 \%$ and 94 $\%$ for PPH, LMPPH and MLMPPH, respectively. At moderate speed adsorbent was distributed throughout providing more active sites. At low shaking most of it was settled at the bottom resulting in concealment of layers and hence less interaction. While with high speed kinetic energies of ions $\left(\mathrm{Pb}^{+2}\right)$ and adsorbent was increased resulting in less interaction between each other Fig. 4a.

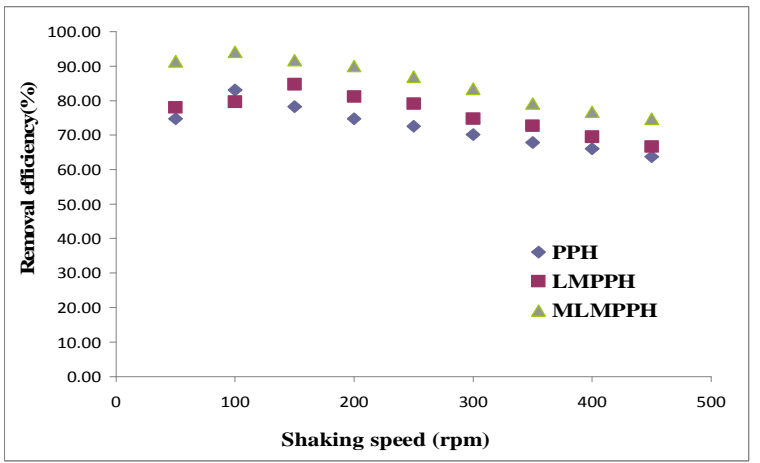

Figure 4a. Effect of shaking speed for lead removal onto PPH, LMPPH and MLMPPH. Adsorbent dose $=0.3 \mathrm{~g}$, Shaking speed $(\mathbf{R P P H})=100 \mathrm{rpm}$, Solution concentration $(25 \mathrm{ppm} / 50 \mathrm{~mL})$, Contact time $=30 \mathrm{~min}$

\section{Contact Time}

The removal efficiency of PPH, LMPPH and MLMPPH for different contact times $(5,10$, 15-70 $\mathrm{min}$ ) were taken. After $60 \mathrm{~min}$ time interval maximum removal efficiency (\%) for PPH was 87 $\%$ and for LMPPH was $89 \%$ and after only 30 min for MLMPPH removal was $96 \%$ Fig. $4 \mathrm{~b}$.

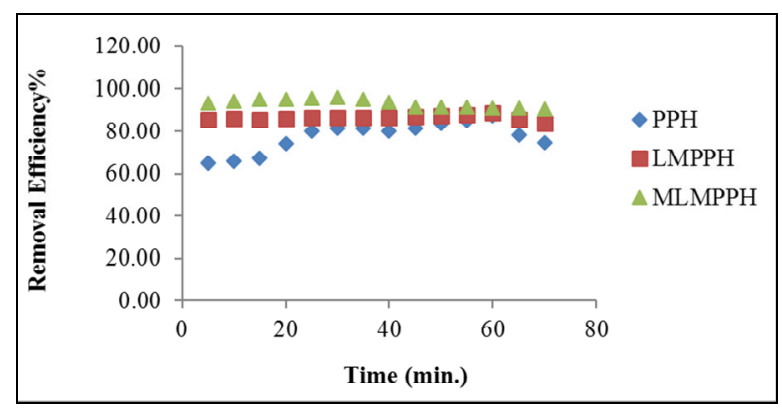

Figure 4b. Effect of contact time for lead removal onto PPH, LMPPH and MLMPPH. Adsorbent dose $=0.3 \mathrm{~g}$, Shaking speed $($ PPH, MLMPPH $)=100 \mathrm{rpm}$, Shaking speed $(\mathrm{LMPPH})=150$ $\mathrm{rpm}$, Solution concentration $(25 \mathrm{ppm} / 50 \mathrm{~mL})$, Temperature $=$ $293 \mathrm{~K}$ 


\section{Mass of Adsorbent}

Maximum adsorption of $\mathrm{Pb}$ (II) was done with $0.5 \mathrm{~g}$ for PPH, $0.3 \mathrm{~g}$ of LMPPH and only 0.1 $\mathrm{g}$ with MLMPPH. Removal capacity of all the three sorbents (PPH, LMPPH, MLMPPH) had increased with the increasing amount of adsorbent and after reaching equilibrium adsorption decreased due to their aggregation and less interaction Fig. 4c.

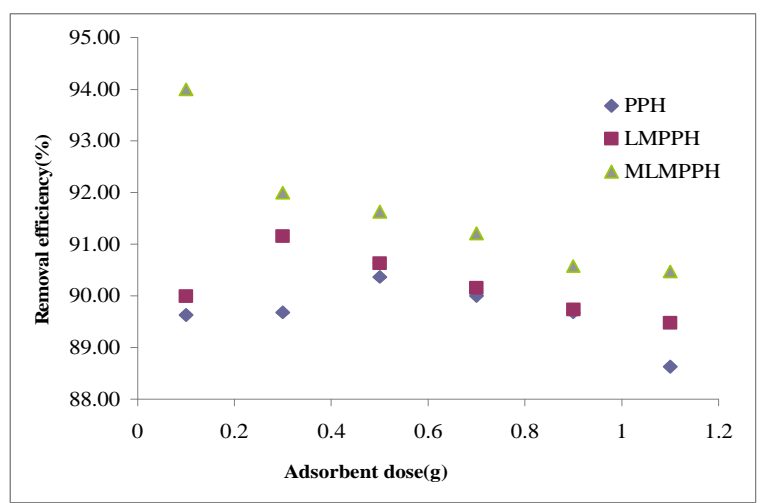

Figure 4c. Effect of adsorbent dose (g) on lead removal onto PPH, LMPPH and MLMPPH. Shaking speed (PPH, MLMPPH) $=100$ rpm, Shaking speed $(\mathrm{LMPPH})=150 \mathrm{rpm}$, Solution concentration $(25 \mathrm{ppm} / 50 \mathrm{~mL})$, Time $=30 \mathrm{~min}$, Temperature $=293 \mathrm{~K}$

\section{pH dependence}

To study the effect of $\mathrm{pH}$ on sorption by PPH, LMPPH and MLMPPH $\mathrm{pH}$ from 3 to 11 was set. Results indicated that MLMPPH and LMPPH had more capability to adsorb $\mathrm{Pb}$ (II) than the $\mathrm{PPH}$ Fig. 4d.

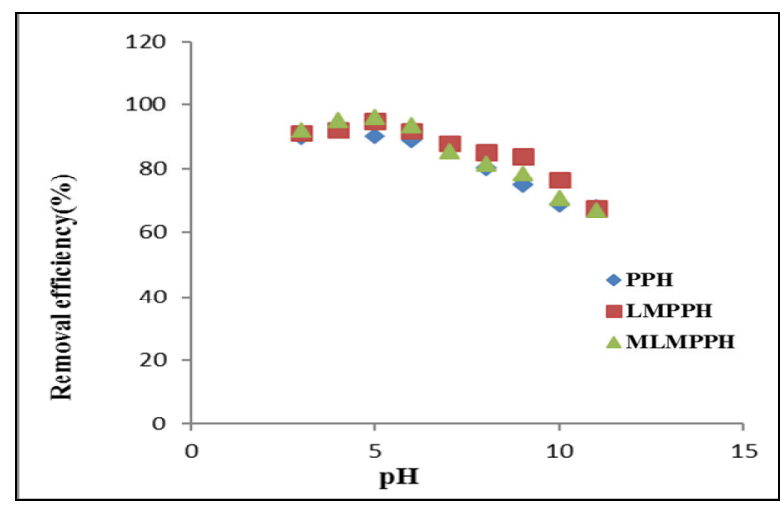

Figure 4d. Effect of pH on lead removal onto PPH, LMPPH and MLMPPH. Adsorbent dose (PPH, LMPPH, MLMPPH) $=0.3 \mathrm{~g}$, Shaking speed $(\mathrm{PPH}, \mathrm{MLMPPH})=100 \mathrm{rpm}$, Shaking speed $(\mathrm{LMPPH})=150 \mathrm{rpm}$, Solution concentration $(25 \mathrm{ppm} / 50 \mathrm{~m} \mathrm{~L})$, temperature $=293 \mathrm{~K}$, Time $=30 \mathrm{~min}$
Acidic conditions are favorable for metal uptake as there is an increase in affinity of potato peels to metal ions. Ionic state of functional group is $\mathrm{pH}$ dependent. PPH mainly has hydroxyl groups where as in LMPPH and MLMPPH there are additional - $\mathrm{COOH}$ groups. At low $\mathrm{pH}$ (less than 3 ) non-ionic -COOH is present and hence less $\mathrm{Pb}^{+2}$ adsorption. Whereas, when $\mathrm{pH}$ is 5 the main specie is $-\mathrm{COO}^{-}$and hence due to electrostatic interaction $\mathrm{Pb}^{+2}$ adsorption is high. At $\mathrm{pH} 5$ there was maximum removal efficiency $(\%)$ of MLMPPH $96 \%$ and $95 \%$ for LMPPH and at $\mathrm{pH}$ 4 was $92 \%$ for PPH.

At higher $\mathrm{pH}$ about 6.0 there was the precipitation of $\mathrm{Pb}^{+2}$ as $\mathrm{Pb}(\mathrm{OH})_{2}$.

$$
\begin{aligned}
& 2 \mathrm{PP}-\mathrm{OH}+\mathrm{Pb}^{+2} \longrightarrow(\mathrm{PPO})_{2} \mathrm{~Pb}^{+2}+2 \mathrm{H}^{+}(\mathrm{PPH}) \\
& \mathrm{PPLM}^{-2}+\mathrm{Pb}^{+2} \longrightarrow \text { PPLM- Pb (LMPPH) }
\end{aligned}
$$

\section{Temperature dependence}

Temperature is one of the major factor to study the phenomenon of adsorption on PPH, LMPPH \& MLMPPH (283 K - $323 \mathrm{~K})$ Fig. 4e. It was observed that $293 \mathrm{~K}$ was the more favorable temperature and removal efficiencies (\%) were 91 $\%, 91 \%$ and $93 \%$ for PPH, LMPPH and MLMPPH. After $293.0 \mathrm{~K}$ there was decrease in removal efficiency due to increased motion and less time of interaction between sorbent and sorbate.

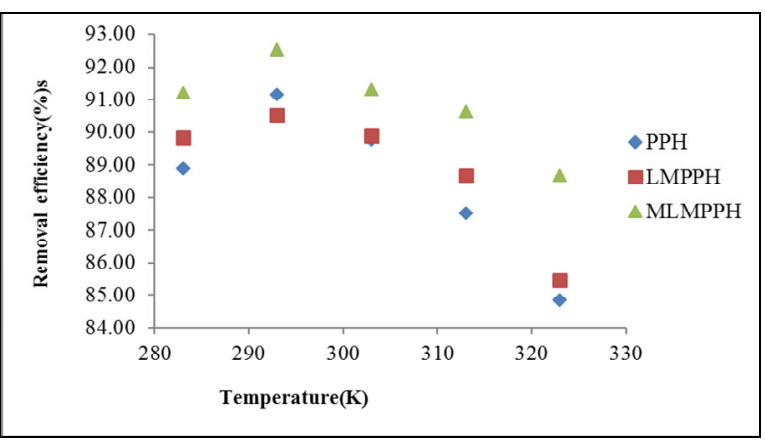

Figure 4e. Effect of temperature $(\mathrm{K})$ on lead removal onto $\mathrm{PPH}$, LMPPH and MLMPPH. Adsorbent dose $=0.3 \mathrm{~g}$, Shaking speed $($ PPH, MLMPPH $)=100 \mathrm{rpm}$, Shaking speed $(\mathrm{LMPPH})=150$ rpm, Solution concentration $(25 \mathrm{ppm} / 50 \mathrm{~mL})$, Time $=30 \mathrm{~min}$

Thermodynamic parameters including $\Delta \mathrm{G}^{\circ}$ (standard free energy), $\Delta \mathrm{H}^{\circ} \quad$ (standard enthalpy) and $\Delta \mathrm{S}^{\circ}$ (standard entropy) were calculated Table 1 using the equation to study the adsorption behavior of the adsorbents. 
$\Delta \mathrm{G}^{\circ}=\Delta \mathrm{H}^{\circ}-\mathrm{T} \Delta \mathrm{S}^{\circ}$

$\Delta \mathrm{G}^{\circ}=-\mathrm{RT} \ln \mathrm{KD}$

$\mathrm{Kd}=\frac{\mathrm{q}_{\mathrm{e}}}{\mathrm{C}_{\mathrm{e}}}$

The negative $\triangle \mathrm{G}$ values for PPH, LMPPH and MLMPPH indicated the spontaneity and feasibility of reaction. Greater value of $\Delta \mathrm{G}$ was for MLMPPH which means that adsorption was more favorable with MLMPPH as compared to LMPPH and $\mathrm{PPH}$. Negative value of $\Delta \mathrm{H}$ means exothermic nature of reaction. Positive $\Delta \mathrm{S}$ value means randomness of binding sites. Among the adsorbents $\mathrm{PPH}$ had more $\Delta \mathrm{S}$ value.

Table 1. Thermodynamic parameters for adsorption of lead onto PPH, LMPPH, MLMPPH.

\begin{tabular}{|c|c|c|c|c|}
\hline Adsorbent & Temperature & $\Delta \mathbf{G}^{\circ}$ & $\Delta \mathbf{H}^{\circ}$ & $\Delta \mathbf{S}^{\circ}$ \\
\hline \multirow{5}{*}{$\mathrm{PPH}$} & 283 & -11.447 & -11.37 & 0.31 \\
\hline & 293 & -11.274 & & \\
\hline & 303 & -12.579 & & \\
\hline & 313 & -13.345 & & \\
\hline & 323 & -14.154 & & \\
\hline \multirow{5}{*}{ LMPPH } & 283 & -11.749 & -10.78 & 0.23 \\
\hline & 293 & -11.005 & & \\
\hline & 303 & -11.950 & & \\
\hline & 313 & -13.345 & & \\
\hline & 323 & -14.154 & & \\
\hline \multirow{5}{*}{ MLMPPH } & 283 & -10.630 & -10.25 & 0.21 \\
\hline & 293 & -10.749 & & \\
\hline & 303 & -11.659 & & \\
\hline & 313 & -12.661 & & \\
\hline & 323 & -13.409 & & \\
\hline
\end{tabular}

\section{Isothermal study}

Langmuir isotherm

Langmuir parametrs including $\mathrm{q}_{\max }$ (maximum sorption capacities), $\mathrm{R}_{\mathrm{L}}$ (separation factor) and $\mathrm{R}^{2}$ (regression coefficient) were calculated from Langmuir isotherm for PPH, LMPPH and MLMPPH (Table 2) using equations.
Table 2. Isothermal parameters for lead sorption onto PPH, LMPPH and MLMPPH.

\begin{tabular}{lllllll}
\hline Adsorbent & \multicolumn{2}{c}{ Langmuir } & \multicolumn{2}{c}{ Freundlich } & \multicolumn{2}{c}{ Temkin } \\
\hline \multirow{4}{*}{ PPH } & $\mathrm{q}_{\max }(\mathrm{mg} / \mathrm{g})$ & 4.992 & $\mathrm{n}$ & 0.272 & $\mathrm{~B}_{\mathrm{T}}$ & 0.030 \\
& $\mathrm{~b}(\mathrm{~L} / \mathrm{g})$ & 9.363 & $\mathrm{~K}_{\mathrm{F}}$ & 1.732 & $\mathrm{~K}_{\mathrm{T}}$ & 1.342 \\
& $\mathrm{R}^{2}$ & 0.991 & $\mathrm{R}^{2}$ & 0.956 & $\mathrm{R}^{2}$ & 0.774 \\
& $\mathrm{R}_{\mathrm{L}}$ & 0.004 & $1 / \mathrm{n}$ & 3.669 & lnkt & 0.294 \\
\hline \multirow{4}{*}{$\mathrm{LMPPH}$} & $\mathrm{q}_{\max }(\mathrm{mg} / \mathrm{g})$ & 5.652 & $\mathrm{n}$ & 0.248 & $\mathrm{~B}_{\mathrm{T}}$ & 0.025 \\
& $\mathrm{~b}(\mathrm{~L} / \mathrm{g})$ & 15.982 & $\mathrm{~K}_{\mathrm{F}}$ & 4.549 & $\mathrm{~K}_{\mathrm{T}}$ & 1.073 \\
& $\mathrm{R}^{2}$ & 0.994 & $\mathrm{R}^{2}$ & 0.966 & $\mathrm{R}^{2}$ & 0.752 \\
& $\mathrm{R}_{\mathrm{L}}$ & 0.002 & $1 / \mathrm{n}$ & 4.017 & $\operatorname{lnkt}$ & 0.070 \\
\cline { 2 - 7 } MLMPPH & $\mathrm{q}_{\max }(\mathrm{mg} / \mathrm{g})$ & 8.710 & $\mathrm{n}$ & 0.333 & $\mathrm{~B}_{\mathrm{T}}$ & 0.029 \\
& $\mathrm{~b}(\mathrm{~L} / \mathrm{g})$ & 31.768 & $\mathrm{~K}_{\mathrm{F}}$ & 5.620 & $\mathrm{~K}_{\mathrm{T}}$ & 1.013 \\
& $\mathrm{R}^{2}$ & 0.894 & $\mathrm{R}^{2}$ & 0.989 & $\mathrm{R}^{2}$ & 0.889 \\
& $\mathrm{R}_{\mathrm{L}}$ & 0.001 & $1 / \mathrm{n}$ & 2.997 & lnkt & 0.013 \\
\hline
\end{tabular}

Note: $\mathrm{q} \max =$ maximum monolayer adsorption capacity $(\mathrm{mg} / \mathrm{g}) ; \mathrm{b}=$ Langmuir constant related to energy of adsorption; qe = adsorption capacity ( $\mathrm{mg}$ of adsorbate per gram of adsorbent); $\mathrm{KF}=$ relative adsorption capacity; $\mathrm{n}=$ adsorption intensity; BT and KT are Temkin constant

$q e=\frac{q \max b c t}{1+b c_{\theta}}$

( $\mathrm{q}_{\mathrm{e}}$ is adsorption capacity in $\mathrm{mg}, \mathrm{q}_{\max }$ is monolayer adsorption capacity of adsorbent $\mathrm{mg} \mathrm{g}^{-1}, \mathrm{~b}$ is Langmuir constant related to energy of adsorption, $\mathrm{C}_{\mathrm{e}}$ is concentration of adsorbate $\mathrm{mg} \mathrm{L}^{-1}$. Factor $\mathrm{b}$ was used to calculate equilibrium parameter $R_{L}$ which explains the favorability of the reaction.

$\mathrm{RL}=\frac{1}{1+b C e}$

MLMPPH had greater qmax value $(8.710$ $\left.\mathrm{mg} \cdot \mathrm{g}^{-1}\right)$ which is the indication of greater number of active sites than LMPPH (5.652 mg.g $\left.{ }^{-1}\right)$ and $\mathrm{PPH}$ (4.992 $\left.\mathrm{mg}^{-1} \mathrm{~g}^{-1}\right) \mathrm{R}_{\mathrm{L}}$ value of $\mathrm{PPH}$, LMPPH and MLMPPH (0.004, 0.002 and $0.001)$ is an indication that reaction was favorable but non-linearity of graphs $(1,2)$ and low $\mathrm{R}^{2}$ values did not satisfy Langmuir isotherms Fig. 5a-b.

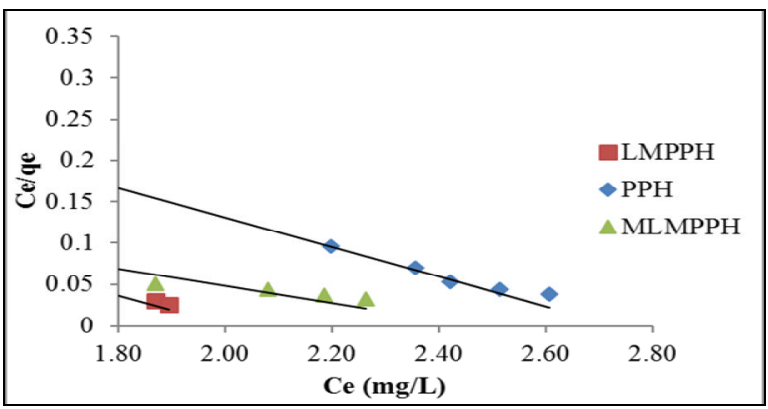

Figure 5a. Langmuir 1 isotherm for PPH, LMPPH, MLMPPH 


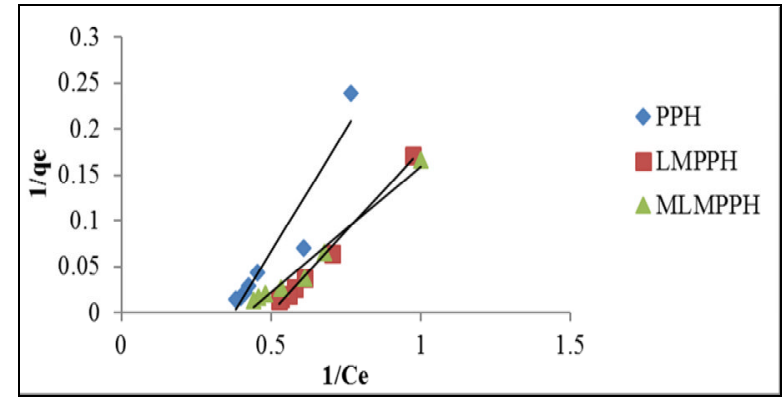

Figure 5b. Langmuir 2 isotherm for PPH, LMPPH, MLMPPH

\section{Frendulich isotherm}

Freundlich model explains multilayer adsorption of metal ions on the heterogeneous surface mainly due to physiosorption mode [42]. The values of $\mathrm{n}$ (adsorption intensity), $\mathrm{K}_{\mathrm{F}}$ (adsorption capacity) and $\mathrm{R}^{2}$ (coefficient of determination) were calculated from Freundlich isotherm. Freundlich equation is:

$q e=K F C e^{1 / n}$

$\left(\mathrm{q}_{\mathrm{e}}\right.$ adsorption capacity (mg of adsorbate per gram of adsorbent), $\mathrm{K}_{\mathrm{F}}$ relative adsorption capacity, $\mathrm{n}$ adsorption intensity, $\mathrm{C}_{\mathrm{e}}$ concentration of solution).

The value of $\mathrm{n}$ increases from $\mathrm{PPH}$, LMPPH and MLMPPH i.e. 0.272, 0.248 and 0.333 Table 2. The $\mathrm{K}_{\mathrm{F}}$ increases from PPH, LMPPH and MLMPPH from $1.732 \mathrm{mg} / \mathrm{g}, 4.549 \mathrm{mg} / \mathrm{g}, 5.620$ $\mathrm{mg} / \mathrm{g}$ because after modification of PPH with lemon juice adsorptive capacity had increased. The linear graph of Freundlich adsorption isotherm and $\mathrm{R}^{2}$ values greater than 0.99 ( $\mathrm{R}$ squared is a statistical measure of how close the data are to the fitted regression line) is according to Frendulich and is an indication of physisorption [42] Fig. 5c.

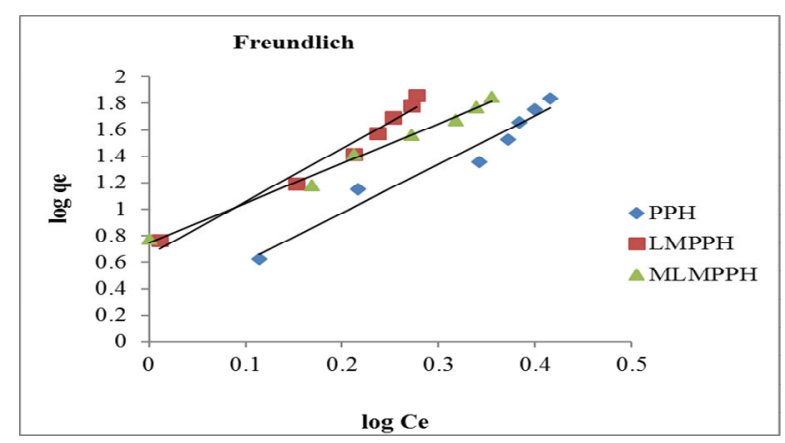

Figure $5 c$. Freundlich isotherm for PPH, LMPPH, MLMPPH

\section{Temkin isotherm}

Temkin adsorption isotherms were used to study the extent of sorption. The values of KT\& BT were calculated Table 2. Temkin equation is:

$q e=B T \ln K T C e$

$\left(\mathrm{B}_{\mathrm{T}}\right.$ and $\mathrm{K}_{\mathrm{T}}$ are Temkin constants, $\mathrm{C}_{\mathrm{e}}$ is concentration of solution) $\mathrm{KT}$ (adsorption capacity) values for PPH, LMPPH and MLMPPH were $1.342 \mathrm{mg} / \mathrm{g}, 1.073 \mathrm{mg} / \mathrm{g}$ and $1.013 \mathrm{mg} / \mathrm{g}$, respectively. $\mathrm{B}_{\mathrm{T}}$ (Heat of adsorption value less than 8 is an indication of weak interaction) for $\mathrm{PPH}, \mathrm{LMPPH}$ and MLMPPH were $0.031 \mathrm{KJ} / \mathrm{mol}$, $0.025 \mathrm{KJ} / \mathrm{mol}$ and $0.029 \mathrm{KJ} / \mathrm{mol}$. $\mathrm{B}_{\mathrm{T}}$ value lower than 8 indicated physiosorption, (weak interaction) and value more than 8 indicated chemisorption during metal ion removal [41]. Here the results of isothermal studies showed physiosorption mode. Temkin isotherm did not hold good for this reaction Fig 5d.

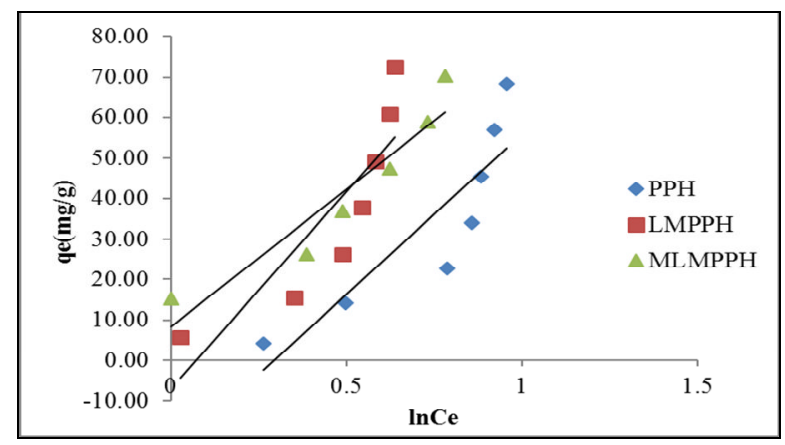

Figure 5d. Temkin isotherm for lead removal onto PPH, LMPPH, MLMPPH

\section{Kinetic study}

In order to determine the sorption rates and possible reaction mechanism pseudo first order, pseudo second order and intraparticle diffusion model were investigated.

Pseudo first order parameters were calculated by:

$\frac{\mathrm{dqt}}{\mathrm{dt}}-\mathrm{k} 1(\mathrm{qe}-\mathrm{qt})$

Ln (qe-qt) $=$ lnqe $-\mathrm{k} 1 \mathrm{t}$ 
(where qt is the amount of lead ions removed at time $t(\mathrm{mg} / \mathrm{g}), q_{e}$ is the adsorption capacity at equilibrium $(\mathrm{mg} / \mathrm{g}), k_{1}$ is the pseudo-first-order rate constant $(1 / \mathrm{min})$, and $t$ is the contact time (min).

Pseudo second order parameters were calculated by:

$$
\begin{aligned}
& \frac{\mathrm{dqt}}{\mathrm{dt}}-\mathrm{K} 2(\mathrm{qe}-\mathrm{qt})^{2} \\
& \frac{\mathrm{t}}{\mathrm{qt}}=\frac{1}{\mathrm{k} 2^{2 \mathrm{qe}^{2}}}+\frac{\mathrm{t}}{\mathrm{qe}}
\end{aligned}
$$

The relation between the experimental qe and calculated qe value is given by $\mathrm{R}^{2}$ values. For pseudo first order the rate constant $\mathrm{K}_{1}$ and difference in qe (exp) and qe (cal) indicated lower $\mathrm{R}^{2}$ values (Table 3) for PPH, LMPPH and MLMPPH which did not fit pseudo-first order model Fig. 6a. For pseudo second order the values of $\mathrm{K}_{2}$ and qe (exp) and qe (cal) were in good agreement with each other for the three adsorbents Table 3 thus the sorption is according to pseudosecond order kinetics Fig $6 \mathrm{~b}$ as the $\mathrm{R}^{2}$ values for PPH, LMPPH and MLMPPH were close to unity [43].

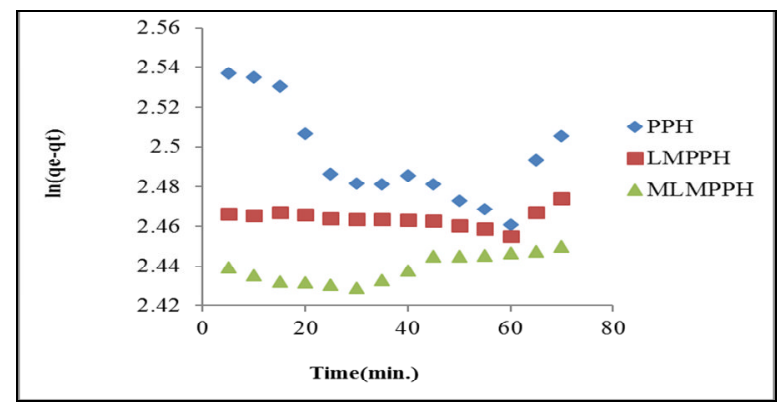

Figure 6a. Pseudo first order kinetics for adsorption of lead onto PPH, LMPPH, MLMPPH

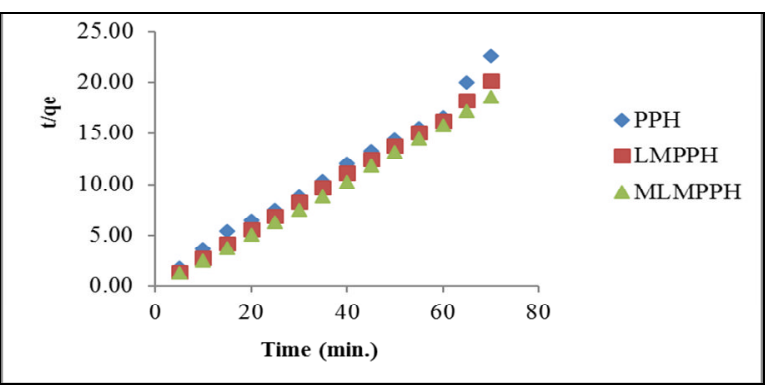

Figure 6 b. Pseudo-second order kinetic model for sorption data of lead onto PPH, LMPPH, MLMPPH

\section{Intra particle diffusion}

The intraparticle diffusion model describes adsorption processes, where the rate of adsorption depends on the speed at which adsorbate diffuses towards adsorbent (i.e., the process is diffusion-controlled), which is presented by equation:

$$
q t=k i d t^{\frac{1}{2}}+C
$$

(kid $(\mathrm{mg} / \mathrm{g} \min )=$ intraparticle diffusion rate constant, $C(\mathrm{mg} / \mathrm{g})=$ constant proportional to the extent of boundary wall thickness). The values of these parameters were calculated for PPH, LMPPH and MLMPPH Table 3.

\begin{tabular}{|c|c|c|c|c|}
\hline \multicolumn{2}{|c|}{ Kinetic Parameters } & \multirow{2}{*}{$\begin{array}{c}\text { PPH } \\
0.984\end{array}$} & \multirow{2}{*}{$\begin{array}{c}\text { LMPPH } \\
0.998\end{array}$} & \multirow{2}{*}{$\begin{array}{c}\text { MLMPPH } \\
0.999\end{array}$} \\
\hline \multirow{4}{*}{$\begin{array}{l}\text { Pseudo } \\
\text { second } \\
\text { order }\end{array}$} & $\mathrm{R}^{2}$ & & & \\
\hline & $\begin{array}{l}\mathrm{K}_{2} \\
\left(\min ^{-1}\right)\end{array}$ & 0.215 & 1.564 & 0.259 \\
\hline & $\begin{array}{l}\text { qe }(\mathrm{mg} / \mathrm{g}) \\
(\mathrm{cal})\end{array}$ & 3.347 & 3.582 & 3.743 \\
\hline & $\begin{array}{l}\text { qe }(\mathrm{mg} / \mathrm{g}) \\
(\exp )\end{array}$ & 3.64 & 3.71 & 4.0 \\
\hline \multirow{4}{*}{$\begin{array}{l}\text { Pseudo first } \\
\text { order }\end{array}$} & $\mathrm{R}^{2}$ & 0.462 & 0.368 & 0.614 \\
\hline & $\begin{array}{l}\mathrm{K}_{1} \\
\left(\min ^{-1}\right)\end{array}$ & 0.0008 & 0.0001 & 0.0003 \\
\hline & lnqe & 2.524 & 2.467 & 2.429 \\
\hline & $\begin{array}{l}\text { qe } \\
(\mathrm{mg} / \mathrm{g})\end{array}$ & 12.489 & 11.795 & 11.349 \\
\hline \multirow{2}{*}{$\begin{array}{l}\text { Intraparticle } \\
\text { diffusion } \\
\text { model }\end{array}$} & $\begin{array}{l}\mathrm{K}_{\mathrm{id}}(\mathrm{mg} / \mathrm{g} \\
\mathrm{min})\end{array}$ & 0.111 & 0.003 & 0.030 \\
\hline & $\mathrm{C}(\mathrm{mg} / \mathrm{g})$ & 2.586 & 3.576 & 4.061 \\
\hline
\end{tabular}

Table 3. Kinetic parameter for lead adsorption using PPH, LMPPH and MLMPPH.

Note: $\mathrm{qe}(\mathrm{mg} / \mathrm{g})=$ sorption capacity at equilibrium; $\mathrm{K} 1(\mathrm{~L} / \mathrm{min})=$ rate constant of pseudo first order adsorption; K2 = rate constant for pseudo second order reaction; kid $(\mathrm{mg} / \mathrm{g} \mathrm{min})=$ intraparticle diffusion rate constant.

In intra particle diffusion model for PPH a nonlinear line not passing through the origin is an indication of the nonavailability of active sites and hence no adsorption. A linear graph is obtained for LMPPH and MLMPPH as compared to the PPH which means availability of active sites and hence adsorption Fig 7. 


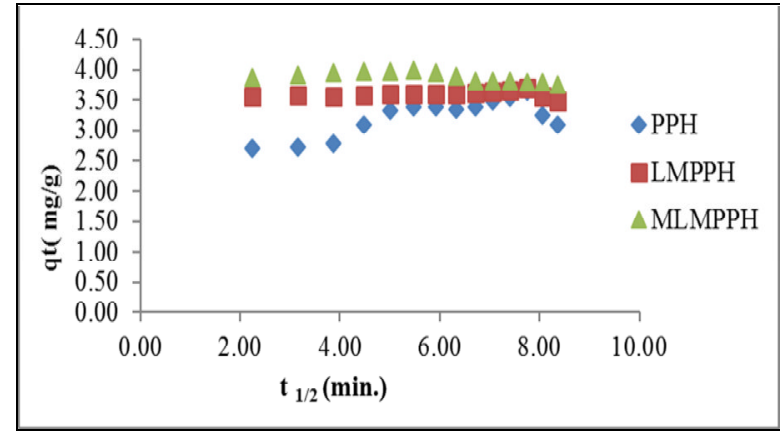

Figure 7. Intraparticle diffusion for adsorption of lead onto PPH, LMPPH, MLMPPH

\section{Column experiment and Thomas kinetic model}

The data obtained from batch conditions were not applicable to column studies where contact time was not sufficiently long enough for the attainment of equilibrium. So to study adsorption kinetics in a column Thomas model has been used [44-45]. The Thomas model is described by equation:

$\frac{C_{q}}{C_{n}}=\frac{1}{1+\operatorname{sxp}\left[\frac{K}{Q}(q o M-\operatorname{CoV})\right]}$

$\left(\mathrm{Ce}=\right.$ effluent solute concentration $\left(\mathrm{mgL}^{-1}\right) \mathrm{Co}=$ Influent solute concentration (mg. $\left.\mathrm{L}^{-1}\right) \mathrm{K}=$ Thomas rate constant $\left(\mathrm{mLmin}^{-1} \cdot \mathrm{mg}^{-1}\right) \mathrm{qo}=$ maximum solid phase concentration of solute $\left.\mathrm{mg}^{-1} \mathrm{~g}^{-1}\right) \mathrm{M}=$ mass of sorbent $(\mathrm{g}) \mathrm{V}=$ throughput volume $(\mathrm{mL}) \mathrm{Q}=$ volumetric flow rate $\left(\mathrm{mLmin}^{-1}\right)$. Thomas equation was linear and is fitted to the breakthrough data to calculate value of $\mathrm{k}$ and qo.

The linearized form of Thomas equation used is:

$\ln \left(\frac{C o}{C \theta}-1\right)=\frac{k q a M}{Q}-\frac{k C o V}{Q}$

Column studies can be studied by plotting breakthrough curves (between $\mathrm{Ce} / \mathrm{Co}$ against time). The kinetic coefficient $\mathrm{KT}$ and the adsorption capacity of the bed qo were determined from the plot. Different amount of biomasses PPH, LMPPH and MLMPPH $(6 \mathrm{~g}, 10 \mathrm{~g})$ were packed. The results of $\mathrm{KT}, \mathrm{R}^{2}$ and qo were given in Table 4. Values of regression coefficients were determined which showed a good fit of the Thomas Kinetic Model. The sorption capacity of PPH, LMPPH \& MLMPPH vary from $2.713 \times 10^{-07}$ $-5.376 \times 10^{-09} \mathrm{mg} / \mathrm{g}$ Table 4 . This decrease in value was due to shortage of $\mathrm{Pb}$ (II) in solution as compared to sorbent amount. Less sharp curves indicate less mass transfer rate and diffused and Sshape curves showed infinite mass transfer rate.

Table 4. Thomas model equation for adsorption of lead onto PPH, LMPPH, MLMPPH for different amount of biomass packed.

\begin{tabular}{lccc}
\hline $\begin{array}{l}\text { Amount of } \\
\text { biomasses packed(g) }\end{array}$ & $\mathbf{R}^{2}$ & $\mathbf{K}_{\mathbf{T}}=$ Intercept/C & $\mathbf{q}_{\mathbf{o}}(\mathbf{~ m g} / \mathbf{g})$ \\
\hline PPH 6 g & 0.862 & 0.002 & $2.713 \times 10^{-07}$ \\
LMPPH 6 g & 0.939 & 0.001 & $2.036 \times 10^{-07}$ \\
MLMPPH 6 g & 0.965 & 0.001 & $1.573 \times 10^{-07}$ \\
PPH 10 g & 0.982 & 0.0001 & $4.612 \times 10^{-08}$ \\
LMPPH 10 g & 0.949 & 0.00001 & $5.376 \times 10^{-09}$ \\
MLMPPH 10 g & 0.977 & 0.0001 & $4.261 \times 10^{-08}$ \\
\hline
\end{tabular}

\section{Effect of bed Height}

Different sorbents (PPH, LMPPH and MLMPPH) were used for column bed with increasing bed height from $6 \mathrm{~cm}$ to $10 \mathrm{~cm}$. Sorption has increased with increasing bed height Fig. 8a due to incresed surface area of biosorbent. The breakthrough time was also increased with the increase in bed height [46].

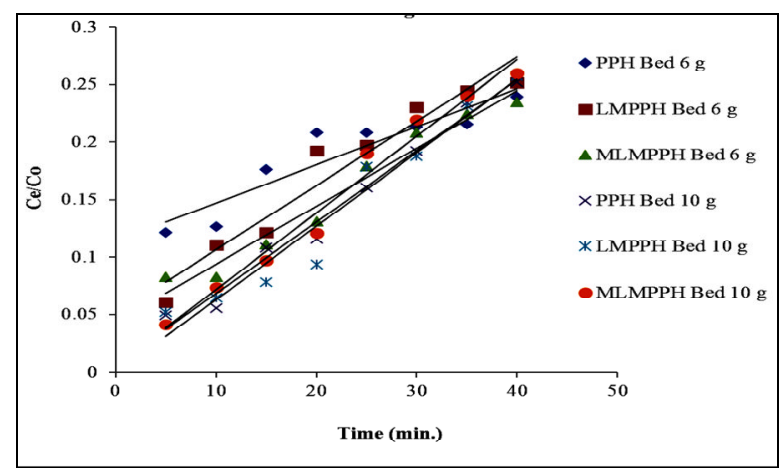

Figure 8a. Breakthrough curves for lead adsorption by PPH, LMPPH, MLMPPH packed bed with different bed height. Average flow rate $6 \mathrm{~mL} / \mathrm{min}$, influent lead concentration $50 \mathrm{ppm}$.

\section{Effect of concentration of sorbate}

Metal ion uptake is decreased with the increasing concentration of sorbate. It showed that increase in concentration of lead (40 ppm) decreases the sorbent metal ratio and hence the uptake of metal Fig. 8b. The biosorbent got saturated earlier and the breakthrough time decreased. 


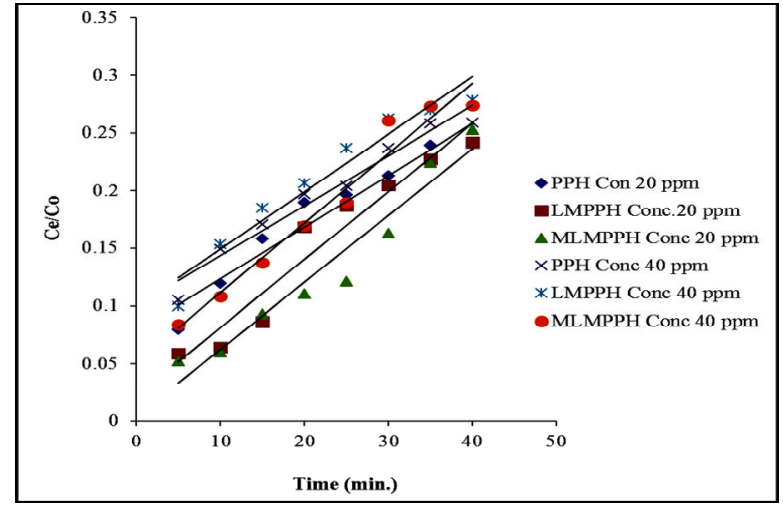

Figure $8 b$. Breakthrough curves for lead adsorption by PPH, LMPPH, MLMPPH packed bed with different influent concentration. Average flow rate $6 \mathrm{~mL} / \mathrm{min}$, influent lead concentration (20-40 ppm), biomass packed $10 \mathrm{~g}$.

\section{Effect of flow rate}

Adsorption highly depends on flow rate. When there was high flow rate of $12 \mathrm{~mL} / \mathrm{min}^{-1}$ adsorption of lead was decreased due to less time of interaction Fig. 8c. Another reason is that the biosorbent got saturated earlier and the breakthrough capacity of biosorbent was decreased.

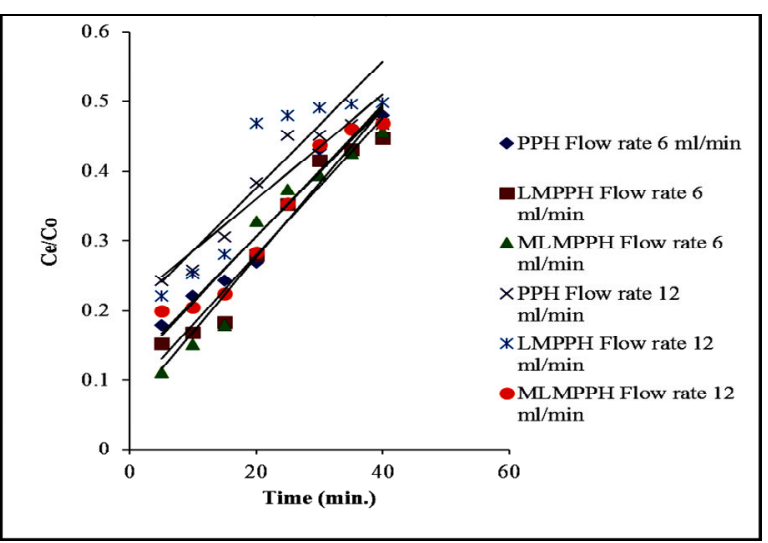

Figure $8 c$. Breakthrough curves for lead adsorption by PPH, LMPPH, MLMPPH packed bed with different influent flow rate, influent lead concentration $(20 \mathrm{ppm})$, biomass packed $10 \mathrm{~g}$.

\section{Conclusion}

It is concluded on the basis of results that PPH, LMPPH and MLMPPH could be successfully used for the removal of lead from aqueous media. MLMPPH adsorbent, prepared by lemon juice \& microwave assisted method offers highest adsorption capacity for removal of $\mathrm{Pb}$ (II) from aqueous solution as compared to $\mathrm{PPH}$ and LMPPH. The surface of MLMPPH has more active sites and that's why it shows highest sorption capacity. Batch and column experiment were conducted and absorption was noted by AAS. Batch experiment was best for removal of lead from aqueous media. Adsorption process was illustrated by pseudo second order kinetics model. Adsorption data was fitted extremely well to the Freundlich isotherm. Thermodynamic calculations revealed that lead adsorption process by $\mathrm{PPH}$, LMPPH and MLMPPH has exothermic nature. The results proved that the MLMPPH has greater sorption capacity for the removal of lead due to presence of $\mathrm{COO}^{-}$group on the surface. It could be used for sorption of different other heavy metals like $\mathrm{Cd}$, As etc. and also for different dyes such as methylene blue etc. from water. Activation by lemon juice is very effective, low cost and at the end of reaction sludge or by products is not formed. This method is easily applicable in agricultural country where a lot of agricultural waste is present and lemon juice is also abundantly available. This method can be applied on industrial scale to remove contaminants from waste water.

\section{Acknowledgement}

All this work is done in the Central Lab of Lahore College for Women University, Jail Road Lahore, Pakistan.

\section{References}

1. M. A. Barakat, Arab. J. Chem., 4 (2011) 361.

https://doi.org/10.1016/j.arabjc.2010.07.019

2. O. B. Akpor, G. O. Ohiobor and T. D. Olaolu, Adv. Biosci. Bioeng., 2 (2014) 37. doi: 10.11648/j.abb.20140204.11

3. P. J. Harvey, H. K. Handley and M. P. Taylor, Environ. Sci. Pollut. Res., 22 (2015) 12276. doi: 10.1007/s11356-015-4349-2

4. Gupta, V. K. and Ali, I. Environmental Water, Advances in Treatment, Remediation and Recycling (In: Ch.1. Ed. 1). Elsevier, Amsterdam, (2012) 232.

https://www.elsevier.com/books/environmen tal-water/gupta/978-0-444-59399-3 
5. P. Roccaro, M. Sgroi and F. G. A. Vagliasindi, Chem. Eng. Trans., 32 (2013) 505.

doi: 10.3303/CET1332085

6. M. Parmar and L. S. Thakur, Int. J. Plant Animal Env. Sci., 3 (2013)143.

https://www.semanticscholar.org/paper/HE AVY-METAL-CU\%2C-NI-AND-ZN\%3ATOXICITY

7. A. E. Burakov, E. V. Galunin, I. V. Burakova, A. E. Kucherova, S. Agarwal, A. G.Tkachev and V. K. Gupta, Ecotoxicol. Environ. Saf., 148 (2018) 702. doi: 10.1016/j.ecoenv.2017.11.034

8. T. K. Tran, K. F. Chiu, C. Y. Lin and H. J. Leu, Int. J. Hydrog. Energy, 42 (2017) 27741.

https://doi.org/10.1016/j.ijhydene.2017.05.1 $\underline{56}$

9. N. Adhoum, L. Monser, N. Bellakhal and J.E. Belgaied, J. Hazard. Mater., 112 (2004) 207.

doi: 10.1016/j.jhazmat.2004.04.018

10. T. A. Kurniawan, G. Y. S Chan, W. H. Lo and S. Babel, Chem. Eng. J., 118 (2006) 83. doi:10.1016/j.cej.2006.01.015

11. A. Azimi, A. Azari, M. Rezakazemi and M. Ansarpour, Chem. Bio. Eng. Rev., 4 (2016) 37.

doi: $10.1002 /$ cben. 201600010

12. H. Eccles, Trends Biotechnol. 17 (1999) 462.

doi: 10.1016/S0167-7799(99)01381-5

13. W. C. Leung, M. F. Wong, H. Chua, W. H. Lo and C. K. Leung, Water Sci. Technol., 41 (2000) 233.

https://doi.org/10.2166/wst.2000.0277

14. G. F. Coelho, A. C. Goncalves Jr., C. R. T. Tarley, J. Casarin, H. Nacke and M. A. Francziskowski, Ecol. Eng., 73 (2014) 514. https://doi.org/10.1016/j.ecoleng.2014.09.10 $\underline{3}$

15. V. K. Gupta, D. Pathania and S. Sharma, Arab. J. Chem., 10 (2017) 2836.

https://doi.org/10.1016/j.arabjc.2013.11.006

16. A. Mittal, J. Mittal, A. Malviya, D. Kaur and V.K. Gupta, J. Colloid. Interf. Sci., 343, (2010) 463. doi: $10.1016 /$ j.jcis.2009.11.060

17. S. A. Banu, S. Nagarani and M. Kirubha, In. J. Eng. Sci. Technol. IJETSR, 3 (2016) 43. https://www.researchgate.net/publication/30 4771144_Preparation_of_Low_Cost_Activa $\underline{\mathrm{t}}$

18. S. Banerjee, S. Dubey, R. K. Gautam, M.C. Chattopadhyaya and Y. C. Sharma, Arab. J. Chem.,12 (2019) 5339. https://doi.org/10.1016/j.arabjc.2016.12.016

19. [19] V. Javanbakht, S. A. Alavi and H. Zilouei, Water Sci. Technol., 69 (2014) 1775.

doi: 10.2166/wst.2013.718.

20. T. K. Naiya, A. K. Bhattacharya, S. Mandal and S. K. Das, J. Hazard. Mater., 163 (2009) 1254.

doi: 10.1016/j.jhazmat.2008.07.119.

21. V. K. Gupta, A. Nayak, S. Agarwal, Environ. Eng. Res., 20 (2015) 1.

doi: https://doi.org/10.4491/eer.2015.018.

22. E. Pehlivan, T. Altun, S. Cetin and M. I. Bhanger, J. Hazard. Mater., 167 (2009) 1203.

doi: 10.1016/j.jhazmat.2009.01.126.

23. K. L. Wasewar, M. Atif, B. Prasad and I. M. Mishra, Desalination, 244 (2009) 66. https://doi.org/10.1016/j.desal.2008.04.036

24. D. H. Reddy, K. Seshaiah, A. V. Reddy, M. M. Rao and M. C. Wang, J. Hazard. Mater., 174 (2010) 831. doi: 10.1016/j.jhazmat.2009.09.128

25. U. Farooq, M. A. Khan, M. Athar and J. A. Kozinski, Chem. Eng. J., 171 (2011) 400. https://doi.org/10.1016/j.cej.2011.03.094

26. J. Anwar, U. Shafique, W. Zaman, M. Salman, A. Dar and S. Anwar, Bioresour. Technol., 101 (2010) 1752. https://doi.org/10.1016/j.biortech.2009.10.02 $\underline{1}$

27. A. H. Jawad, N. F. H. Mamat, M. F. Abdullah and K. Ismail, Desalin. Water Treat., 59 (2017) 210. doi:10.5004/dwt.2016.0097

28. M. C. Basso, E. G. Cerrella and A. L. Cukierman, Ind. Eng. Chem. Res., 41, (2002) 3580. doi: $10.1021 / \mathrm{ie} 020023 \mathrm{~h}$

29. S. Chen, Q. Yue, B. Gao and X. Xu, J. Colloid Interf. Sci., 349 (2010) 256. doi: 10.1016/j.jcis.2010.05.057

30. S. Deng, R. Bai and J. P. Chen, J. Colloid Interf. Sci., 260 (2003) 265. 
https://doi.org/10.1016/S0021-9797 (02)00243-6

31. L. C. Oliveira, E. Pereira, I.R. Guimaraes, A. Vallone, M. Pereira, J. Mesquita and K. Sapag, J. Hazard. Mater., 165 (2009) 87. doi: 10.1016/j.jhazmat.2008.09.064

32. Z. Liu, Y. Huang and G. Zhao, Bio. Res., 11 (2016) 3178. doi: 10.15376/biores.11.2.3178-3190

33. D. Schwantes, A. C. G. Jr., G. F. Coelho, M. A. Campagnolo, D. C. Dragunski, C. R. T. Tarley, A. J. Miola, and E. A.V. Leismann, J. Chem., 2016 (2016) 15. http://dx.doi.org/10.1155/2016/3694174

34. M. U. Ruimin, W. Minxiang, B. U. Qingwei, L. Dong and Z. Yanli, IOP Conf. Ser. Earth Environ. Sci., 108 (2018) 22063. doi :10.1088/1755-1315/108/2/022063

35. W. S. Wan Ngah, M. A. K. M. Hanafiah, Bioresour. Technol., 99 (2008) 3935. https://doi.org/10.1016/j.biortech.2007.06.01 $\underline{1}$

36. Argun, Mehmet and Dursun, Sukru, J. Int. Environ. Appl. Sci., 1 (2006) 27. https://www.researchgate.net/publication/26 6888800 Removal of heavy metal ions

37. U. Farooq, M. Khan, M. Athar, J. A. Kozinski, Chem. Eng. J., 171 (2011) 400. doi: 10.1016/j.cej.2011.03.094.

38. M. Salman, M. Athar, U. Farooq, S. Rauf and U. Habiba, Kor. J. Chem. Eng., 31 (2014) 467. doi: $10.1007 / \mathrm{s} 11814-013-0264-8$
39. G. Socrates, Infrared Characteristic Group Frequencies, John Wiely, Hoboken, NJ, USA, 2nd edition, (1994). https://www.worldcat.org/title/infraredcharacteristic-groupfrequencies/oclc/4665132/editions

40. T. Mathimani and A. Pugazhendhi, Biocatal. Agric. Biotechnol., 17 (2019) 326. doi: 10.1016/j.bcab.2018.12.007

41. M. Salman, R. Rehman, U. Farooq, A. Tahir, L. Mitu, J. Chem., 2020 ( 2020) 11. https://doi.org/10.1155/2020/8269643

42. M. Athar, U. Farooq, M. Aslam and M. Salman, Appl. Water Sci., 3 (2013) 665. https://doi.org/10.1007/s13201-013-0115-0

43. K. D. Kowanga, E. Gatebe, G. O. Mauti, E. M. Mauti, J. Phytopharmacol., 5 (2016) 71.

http://www.phytopharmajournal.com/Vol5 I ssue2_06.pdf

44. A. Ghribi and M. Chlendi, Asian J. Textile, 1 (2011) 161. doi: 10.3923/ajt.2011.161.171

45. J. L. Cervantes, D. I. S. Machado, R. G. S. Duarte and M. A. C. Murrieta, Adsorpt. Sci. Technol., 36 (2018) 215. doi: $10.1177 / 0263617416688021$

46. D. S. Malik, C. K. Jain, A. K. Yadav, Chem. Bio. Eng. Rev., 5 (2018) 1. doi: 10.1002/cben.201700018. 